\title{
The Dip-slide in Urology
}

\author{
F. R. JACKAMAN， J. H. DARRELL， R. SHACKMAN
}

British Medical fournal, 1973, 1, 207-208

\section{Summary}

To assess the value of the Uricult dip-slide in a hospital urological unit, bacteriological examination of 1,033 urine specimens was compared by this technique and by conventional methods. In $87 \%$ of cases identical results were obtained using the dip-slides and the standard laboratory culture plates. Insignificant differences occurred in $10 \%$, and a serious discrepancy between the two methods was found in only $3 \%$. The Uricult dip-slide technique is valuable as a bacteriological screening procedure in urological practice but subculturing from the slide is not recommended except in special circumstances.

\section{Introduction}

Routine bacteriological examination of urine in large hospitals imposes a heavy work load on bacteriology departments and, as most specimens are found to show no significant abnormality, much of the work could be regarded as superfluous. If it were possible to determine the negative urines by a simple, reliable screening method there would be a great saving of laboratory work and time. Application of the dip-slide technique, which has been found to be satisfactory in domiciliary practice (Mackey and Sandys, 1965; Guttmann and Naylor, 1967), paediatric practice (Arneil et al., 1970), and in screening asymptomatic populations such as school children (Parsons, 1972), seemed an attractive possibility and it was therefore decided to undertake an assessment of the method in the management of patients in a urology unit.

The Uricult dip-slide was used. This consists of a polyethylene slide $2 \mathrm{~cm}$ by $5 \mathrm{~cm}$ attached to the screw top of its plastic container. One surface of the slide is coated with MacConkey's medium and the other with nutrient agar or C.L.E.D. medium (cysteine lactose electrolyte-deficient agar). The primary objective of the study was to compare results obtained when using the Uricult dip-slide with the plate methods in standard use in the department of bacteriology. The opportunity was taken to determine the significance of microscopical pyuria in screening of urines, and to see if definitive bacteriology was possible by using colonies from the Uricult slide.

\section{Methods}

Urine specimens were obtained from all patients in the urological and renal transplant wards twice weekly, all new patients in the urological outpatient clinic, all patients attending the renal transplant follow-up clinic, and all patients admitted with acute urological conditions. Most were midstream or catheter specimens but some were obtained from patients with ileal conduit and ureterosigmoidostomy urinary diversions. Waxed cartons were used for collecting the specimens, and inoculation of the dip-slides was carried out immediately by dipping them into

Urological Unit and Department of Bacteriology, Royal Postgraduate Medical School, Hammersmith Hospital, London Graduate

F. R. JACKAMAN, M.B., F.R.C.S., Urological Registrar

J. H. DARRELL, M.B., M.R.C.PATH., Reader in Bacteriology

R. SHACKMAN, M.B., F.R.C.S., Professor of Urology the freshly voided specimens. In those patients with acute urinary tract infection who were able to pass only small volumes of urine because of frequency, the Uricult slide container, when filled with urine, was adequate to provide sufficient depth to cover the slide completely. The inoculated dip-slides and urine specimens from which they had been prepared were sent to the bacteriology department without delay for concurrent examination. Microscopy of the deposit was carried out and the dipslides were incubated at $37^{\circ} \mathrm{C}$ for 18 hours or overnight, together with duplicate cultures prepared by the plate methods in routine use. Both the dip-slides and plates were read by one bacteriologist. Degrees of bacterial growth on the dip-slides and on the plates were assigned to one of three categories: (1) no growth ( $<300$ colonies $/ \mathrm{ml}$ ), (2) no significant growth $\left(10^{3}-10^{5}\right.$ colonies $/ \mathrm{ml})$, and (3) significant growth $\left(>10^{5}\right.$ colonies $/ \mathrm{ml}$ ) when using the calibration chart supplied by the makers. In some cases, colonies on the dip-slides were used as the source of the cultures for bacterial identification and antibiotic sensitivity tests.

\section{Results}

Between January and April 1972, 1,033 urine specimens were examined. There was no growth on the dip-slides or on the control plates in 625 . There was no significant growth on both in 78 specimens, and there was significant growth on both in 198. The two methods, therefore, gave identical results in $87 \%$ of cases. A breakdown of results where there were differences shows that in $\mathbf{8 5}$ specimens there was no significant growth on the dip-slide and no growth on the plate, in 20 there was no growth on the dip-slide and no significant growth on the plate, in 19 there was significant growth on the dip-slide but no growth or no significant growth on the plate, and in 8 there was no growth or no significant growth on the dip-slide and significant growth on the plate. The correlation between the two methods is summarized in the chart. The shaded groups in this chart are those in which there is agreement of clinical significance. The incidence of significant discrepancy between the two methods was 27 out of 1,033 .

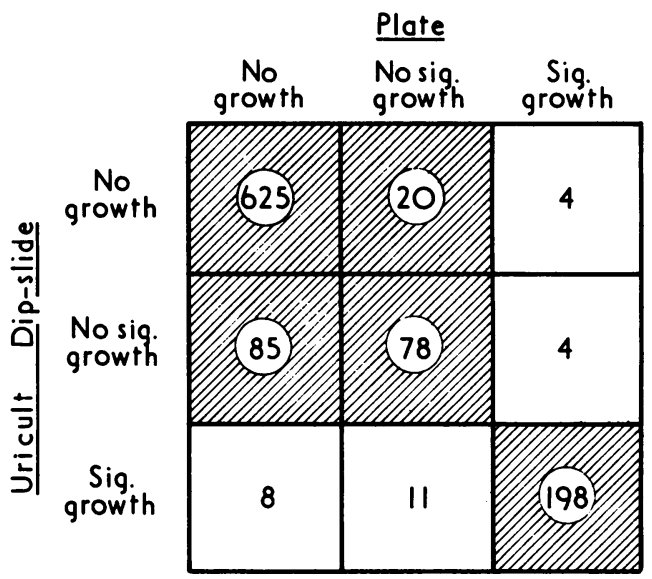

Correlation between the two methods of culture.

Significant pyuria ( $>20$ pus cells per high power field of centrifuged urine) was found in 77 out of 184 urines (42\%) which gave significant growth on standard plates. Significant pyuria was also found in 56 out of 718 urines $(8 \%)$ which 
gave no growth; in 26 out of 56 urines there had been recent antibacterial therapy, and in the remaining 30 there had been recent surgery (see table). It was possible to identify organisms without difficulty in only 21 out of 50 urines $(42 \%)$ when subcultures were taken directly from the slide. This was due to the presence of mixed growth not readily detectable on the small area of the slide, when growth was heavy.

Diagnosis of 30 Patients with Sterile Pyuria Who Had Not Received Antibacterial Therapy

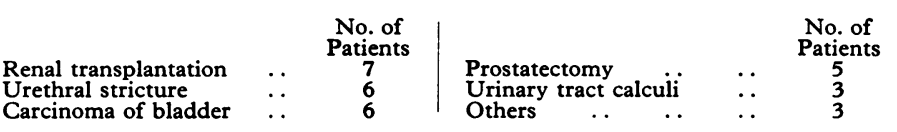

\section{Discussion}

This study has shown that the Uricult dip-slide used in a urological and transplant unit gave results that were identical with those obtained by standard methods in $87 \%$ of cases, and even when there was disagreement $(13 \%)$ the tendency was for the dip-slide method to err on the side of false-positive rather than false-negative results, using the standard plate method as the criterion of correctness. Serious discrepancy was noted in only $3 \%$.

Pyuria was absent in most cases in which bacteriological cultures proved to be negative, and in the cases in which sterile pyuria was found antibacterial therapy or recent urological surgery could be indicted as the cause. The absence of significant pyuria in more than $50 \%$ of cases with significant bacterial growth could imply that microscopy of the urine is not essential in cases of urinary tract infection. Indeed it has been stated (Kass, 1956) that high bacterial concentrations alone are synonymous with urinary tract infection and that treatment should be instituted on this basis. However, we prefer first to obtain confirmation by repeated positive cultures.

Apart from the fact that the dip-slide technique has been shown to be invaluable for use in domiciliary practice, particularly because the slides can be sent by post to the bacteriology laboratory, the present study has confirmed its reliability as a screening procedure in a hospital urological unit. A preliminary dip-slide examination reduces the laboratory work load by screening off negative urines; in those cases in which there is a significant growth further investigations by standard methods can be instituted. Outpatients can present a special problem when a second specimen of urine is required in cases with a positive dip-slide. It is possible for definitive bacteriology to be done by subculturing the colonies from the dip-slide if a second specimen of urine is not available. As mixed cultures frequently occur, however, and preliminary purification is sometimes necessary, this means that the laboratory work load will be increased rather than decreased, defeating the original object of the method. It is probably better, therefore, to use the Uricult dip-slide primarily as a screening procedure unless subsequent urine specimens are not available.

We are most grateful to Mr. R. A. Lambert, chief technician in the department of bacteriology, for his help in reading the Uricult slides and the plates. We also thank Dr. J. Moodie, of Bristol Laboratories, Slough, for providing the Uricult slides.

\section{References}

Arneil, G. C., McAllister, T. A., and Kay, P. (1970). Lancet, 1, 119 Guttmann, D., and Naylor, G. R. E. (1967). British Medical fournal, 2,343 Kass, E. H. (1956). Transactions of the Association of American Physicians, $69,56$.

Mackey, J. P., and Sandys, G. H. (1965). British Medical Fournal, 2, 1286. Parsons, V. (1972). In preparation.

\title{
Correction of Adverse Reponse to Suxamethonium of Susceptible Pigs
}

\author{
DAVID LISTER
}

British Medical fournal, 1973, 1, 208-210

\section{Summary}

The adverse response to suxamethonium in susceptible pigs has been shown to be associated with changes in serum free thyroxine index. Pyrexia and acidosis can be controlled by the cautious administration of L-triiodothyronine (T-3). Successful correction has been achieved in eight episodes, and in six of these, where it was intended, rapid, uneventful, and complete recovery occurred.

\section{Introduction}

In the course of investigating the hyperpyrexic response to suxamethonium in over a hundred susceptible pigs, we showed

\footnotetext{
Agricultural Research Council, Meat Research Institute, Langford, Bristol BS18 7DY

DAVID LISTER, B.SC., PH.D., Principal Scientific Officer
}

that the initial response and its subsequent development were associated with fluxes in the free thyroid hormone as represented by the free thyroxine index in the serum (Lister and Lucke, 1972). All the animals suffered an immediate and noticeable fall in their relatively high serum free thyroxine index, which is the reverse of the change often found during anaesthesia (Oyama et al., 1969). The subsequent pattern of the response depended on the extent to which restoration of the usual free thyroxine index was accomplished. If there was little or no increase in the lowered value for serum free thyroxine index after suxamethonium challenge, death occurred relatively quickly with only moderate pyrexia and acidosis, and there was no evidence of rigor of the musculature. If serum free thyroxine index was increased to a greater extent the acidosis was progressive (blood $\mathrm{pH}<6.6$ and $\mathrm{PCO}_{2}>200 \mathrm{~mm} \mathrm{Hg}$ ), hyperpyrexia developed and rigor occurred usually some time before, but always by the time of death. In all cases the serum free thyroxine index at death was low or falling.

This preliminary note, which outlines the general principles by which the successful correction of the suxamethonium response in eight pigs has been achieved by the administration of thyroid hormone, is prompted by the urgent need to define the aetiology and provide empirically based treatment for this characteristically fatal response in human patients. 